\title{
Cuando los sonidos se hacen arte: la ciudad y la radio*
}

\author{
Ray Gallon \\ Universidad de Barcelona \\ ray@culturecom.net
}

\begin{abstract}
Resumen
En este texto se reflexiona en torno al ruido como materia prima de composición sonora, visto desde una concepción artística. Se propone que, a partir de una re-contextualización del ruido, éste se convierte en sonido, y con ello se pueden crear múltiples juegos para el oído, generando incluso situaciones dramáticas y narrativas. Específicamente, se hará referencia a diversas composiciones emanadas del Hörspiel Studio, las que constituían un conjunto de retratos sonoros de ciudades de todo el mundo, en una serie titulada "Metropolis", de las cuales tuve el privilegio de participar en la creación del retrato sonoro de Barcelona, en el año 2001.
\end{abstract}

Palabras clave

Ruido, sonido, retratos sonoros, ciudad, Barcelona.

\section{When sounds become art: the city and the radio}

\begin{abstract}
This text reflects on the noise as a raw material of sound composition, seen from an artistic conception. It is proposed that, from a re-contextualization of the noise, it becomes sound, and with this it can create multiple plays for the ear, generating even dramatic and narrative situations. Specifically, a reference will be made to various compositions emanating from the Hörspiel Studio, which constituted a set of sound portraits of cities around the world, in a series entitled "Metropolis", of which I had the privilege of participating in the creation of the sound portrait of Barcelona, in the year 2001.
\end{abstract}

Keywords

Noise, sound, sound portraits, city, Barcelona.

* Recibido: 15 de abril de 2017 / Aceptado: 31 de mayo de 2017. 
Ray Gallon. Cuando los sonidos se hacen arte: la ciudad y la radio.

\section{Quando os sons se tornam arte: a cidade e rádio}

Resumo

Neste texto aborda-se o ruído como a matéria-prima da composição do som, visto a partir de uma concepção artística. Propõe-se que, a partir de uma re-contextualização de barulho, torna-se em som, e, assim, cria vários jogos para o ouvido, mesmo situações dramáticas e narrativas. Especificamente, a referência a várias composições que emanam de Hörspiel Studio, que formou um conjunto de retratos de som de cidades ao redor do mundo em uma série intitulada "Metropolis", do qual tive o privilégio de participar na criação do retrato sonoro de Barcelona, em 2001.

Palavras-chave

Ruído, som, retratos sonoros, cidade, Barcelona. 
Normalmente sólo hablamos de "ruidos" cuando nos molestan. Cuando nos interesan, los llamamos "sonidos". Así, la idea de ruido como materia prima de composición sonora no entra fácilmente en nuestra concepción artística. No obstante, si sólo entendemos el ruido como una molestia, todo nuestro entorno acústico también se convierte únicamente en una molestia. Por ello, tenemos una gran cantidad de asociaciones sociales luchando contra el ruido y, prácticamente, ninguna entidad que luche por una gestión positiva y de calidad del territorio sonoro, sobre todo en entornos urbanizados.

De todos modos, si identificamos los ruidos aisladamente o los ponemos en un contexto no habitual, éstos pueden convertirse en elementos con los que podemos componer el entorno, tal como lo hacemos cuando componemos música. En consecuencia, los ruidos se convierten en "sonidos" cuando los re-contextualizamos.

Esta re-contextualización es una de las características naturales de la radio, que a menudo se olvida en el día a día de la programación radiofónica. Volvemos a contextualizar los sonidos cada vez que presentamos una grabación del exterior, ya sea en un reportaje, una entrevista o una canción. En cada audición presentamos un evento fuera de su lugar y de su tiempo, amputado de su entorno. En la radio, hacemos recreaciones sonoras de una realidad que ya no existe.

Cuando los artistas comienzan a jugar con ruidos (sonidos), están creando juegos para el oído. En alemán, el juego para el oído se llama Hörspiel-literalmente, "escucha-juego." Es la palabra para identificar el radiodrama, una forma radiofónica casi desaparecida en nuestra época post-televisiva, pero muy extendida en los años 1960. En esa época, el productor alemán Klaus Schöning, de la Westdeutscher Rundfunk (WDR) en Colonia, propuso: "¿y si fueran los sonidos, los que jugaran...?".

La idea de su neues Hörspiel, nuevo radiodrama (o nuevo juego para el oído), se basaba en la utilización del sonido, y sólo el sonido, para crear situaciones dramáticas y narrativas, sin texto. La voz no está prohibida en el neues Hörspiel, pero solo tiene la categoría de ruido, como cualquier otro sonido. La narrativa o la idea composicional se explica únicamente a través de los sonidos. Schöning tenía la creencia de que una obra dramática de estas características sería universalmente comprensible para un público internacional (Schöning, 1970).

Su programa, Hörspiel Studio, también incluía deconstrucciones literarias, como Und Die Wörter, de Gerhard Rühm y Klaus Schöning (1973), o híbridos de música y drama, como Der Tribun, de Mauricio Kagel (1979). En 1991, Schöning abandonó el equipo de redacción de Hörspiel Studio y el programa se convirtió en Studio für Akustische Kunst (Estudio para el Arte Acústico). 
Muy pronto, diversas composiciones destacaron dentro del Hörspiel Studio. Constituían un conjunto de retratos sonoros de ciudades de todo el mundo, en una serie titulada "Metropolis". Schöning encargó a varios artistas la creación de impresiones personales acústicas (la composición de una subjetividad auditiva), a través de los ruidos de la vida urbana. Diversas ciudades fueron representadas por diferentes artistas en distintas épocas, con retratos diferentes. Algunas de las ciudades seleccionadas fueron:

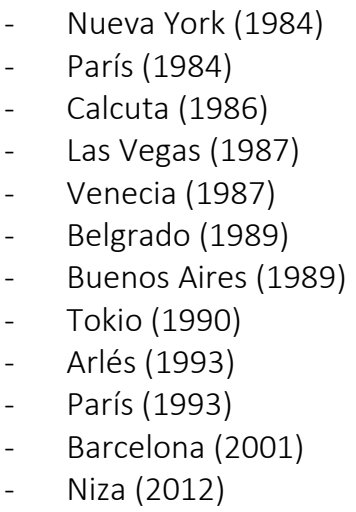

Yo tuve el privilegio de participar con la creación del retrato sonoro de Barcelona, en el año 2001.

En aquella época, yo era un recién llegado a la ciudad y la producción fue para mí una oportunidad única, que me dio la ocasión de realizar un descubrimiento personal de la misma, donde pasé más de diez meses grabando el relato sonoro.

En mi exploración, observé que Barcelona tenía la estructura de una cebolla, en capas concéntricas:

- El corazón romano en el centro de la ciudad

- El núcleo gótico alrededor del centro

- La anilla modernista y expansiva del Eixample

- La corona "incorporada", con pueblos añadidos recientemente a la ciudad

- La capa contemporánea que barniza dinámicamente todos los eslabones.

Me hablaron, en ese momento, de la expresión catalana de "ser de la ceba", que formula la idea de "ser del terruño", y por eso decidí inmediatamente que el título del retrato debía ser "Barcelona de la ceba". 
La organización de la obra siguió la estructura anular que se ha señalado y diseñó un itinerario sonoro en forma de capas, como una cebolla. Un ruido discernible fue la "señal acústica" que marcó el tránsito de una anilla a la otra. Esta señal se compuso de dos sonidos emblemáticos de la ciudad:

- La campana de la iglesia de Santa María del Mar, en el barrio gótico

- Los "butaneros" o cargadores de butano (ruido identificado oficialmente como un componente del patrimonio intangible de la ciudad de Barcelona).

Por casualidad, los dos sonidos-señales se encuentran en la grabación en la misma secuencia, creando un contínuum en discontinuidad que es muy propio de esta ciudad, llena de contradicciones.

Después de terminar el trabajo, no estaba seguro de que esta forma de secuencia "en capas" fuera audible para la mayoría de la audiencia, pero, sin esta estructura interna, no hubiera podido construir una obra coherente. Al igual que en una forma musical, como el rondón o la sonata, la forma que escogí en mi representación mental no es una abstracción, sino una guía. Es, en realidad, una guía para la grabación, al igual que para el mezclado final. A diferencia de estas formas musicales normativas, mi estructura es el resultado de un proceso subjetivo, personal y voluntario.

El contenido acústico de la obra también fue seleccionado para crear una suerte de subjetividad auditiva mediante la cual el compositor pretende, tal vez de modo idealista, que el oyente capte ese lugar de escucha que ha sido el del compositor. Por este motivo, el lugar donde se coloca el micrófono para grabar es más importante que la selección del sonido que se registra. Al igual que los ruidos producidos en un momento determinado, la acústica del entorno en su contexto funcionaba como materia plástica sonora.

Lo que más me interesaba captar era lo siguiente:

- Lugares o recorridos donde el oyente emerge, desplazándose de un espacio acústico a otro y aportando con ello un cambio acústico particular.

- Lugares donde se escuchan simultáneamente eventos sonoros diferentes en cada uno de los oídos.

- Puntos o recorridos de mezcla sonora natural.

- Sonidos emblemáticos, culturales o personales.

- Contraste de un mismo sonido, sobre todo entre dos o tres posiciones de escucha, a distancias diferentes.

El resultado fue un viaje muy cerca del suelo, en círculos concéntricos, un collage acústico de ruidos que definen Barcelona o, al menos, que lo hacen en la representación mental que yo tenía de la ciudad en aquella época. También es 
cierto que, dada la situación política y social de hoy en día, no se puede escuchar la obra de la misma manera que en 2001, cuando la creé. La ventaja es que una obra de este tipo se puede escuchar muchas veces y en cada ocasión será una experiencia nueva, debido a la naturaleza subjetiva de la obra y al contexto singular en que ocurre el acto de escuchar.

Por lo tanto, siempre hay una historia dentro de la obra. No es necesariamente una historia de narrativa lineal; es una historia de paseos fragmentados y parciales, como si saltásemos de un agujero de gusano a otro por el universo acústico de la ciudad, sólo deteniéndonos para explorar un rato en algún lugar, antes de continuar nuestro juego radiofónico para el oído.

Mientras consigas percibir de la forma más pasiva posible y el paisaje te envuelva sin que permitas que ningún objeto en particular retenga tu atención; si el paisaje entra en ti sin que lo sientas, si su geometría te atraviesa sin poseerte, sin que interpretes; si, aún así, eres capaz de oír, de escuchar, te encontrarás ante el sonido de lo más íntimo; aquel que se desvanece en cuanto el mundo entra en ti de la mano de la escucha, la mirada o cualquier otra percepción exterior suficientemente intensa y atenta; suficientemente profunda. Dejarás de escucharlo siempre que se perfile la particularidad de los límites del mundo, se revelen sus formas, sus cumbres, sus valles, y cada objeto se instale como por arte de magia en su plano, es decir, a la profundidad relativa del campo acústico que le corresponde.

\section{Referencias}

\section{Bibliografía}

Schöning, Klaus (1970). Neues Hörspiel. Fráncfort del Meno: Shurkamp.

\section{Discografía}

Kagel, Mauricio (1979). Der Tribun. Hörspiel für einen politischen Redner, Marschklänge und Lautsprecher (CD). 50 min. Alemania: Wergo.

Rühm, Gerhard; Schöning, Klaus (1973). Ophelia Und Die Wörter (LP). Alemania: Deutsche Grammophon. 